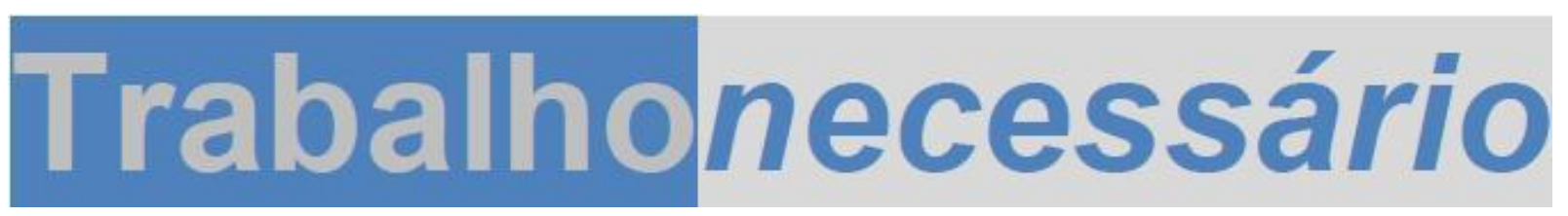

Issn: 1808 - 799X

ano 12, no $18-2014$

\title{
CARACTERÍSTICAS E FUNDAMENTOS DA CONCEPÇÃO THOMPSIANA DE CULTURA E REPERCUSSÕES NA EDỦCAÇÃO
}

\author{
Ângela Maria Souza Martins ${ }^{1}$ \\ Lúcia Maria Wanderley Neves ${ }^{2}$
}

\section{Resumo}

O texto apresenta, sucintamente, algumas das características e fundamentos da concepção thompsiana de cultura imprescindíveis para a compreensão da relação entre história e cultura e suas repercussões no campo educacional. Demarca a especificidade da sua concepção de cultura na tradição marxista e em outras acepções contemporâneas. Aponta como características das manifestações culturais: seu imbricamento com as lutas de classe, sua dialeticidade com o desenvolvimento das forças produtivas materiais, bem como o duplo caráter, amplo e restrito, de suas manifestações. Como fundamentos de sua concepção de cultura, ressalta o modo como Edward $\mathrm{P}$. Thompson concebe a relação entre base e superestrutura, entre ser social e consciência social e a importância atribuída por ele à interface entre experiência, hegemonia e cultura na construção e na dinâmica do ser social. Destaca ainda as repercussões de suas contribuições teórico-metodológicas para a compreensão dos objetivos educacionais nas sociedades urbano-industriais e para a delimitação dos fundamentos da prática pedagógica na atualidade.

Palavras-chave: marxismo; cultura; educação.

\footnotetext{
${ }^{1}$ Professora da Universidade Federal do Estado do Rio de Janeiro (UNIRIO) e pesquisadora do Núcleo de Estudos e Pesquisas em História da Educação Brasileira (NEPHEB/HISTEDBR). Doutora em Educação, pela Universidade Federal do Rio de Janeiro. asmartins22@gmail.com

2 Professora. Pesquisadora do Coletivo de Estudos de Política Educacional, Conselho Nacional de Desenvolvimento Científico e Tecnológico/Universidade Federal de Juiz de Fora (CNPQ/UFJF)], Núcleo do Rio de Janeiro. Doutora em Educação, pela Universidade Federal do Rio de Janeiro. lucianeves@globo.com
} 


\title{
Trabalhonecessário
}

Issn: $1808-799 X$

ano 12, no $18-2014$

\begin{abstract}
The text briefly presents some of the characteristics and fundamentals of thompsian conception essential for understanding the relationship between history and culture and its impact on the educational field. Demarcates the specificity of their conception of culture in the Marxist tradition and other contemporary meanings. Points as characteristic of cultural manifestations: its interrelation with the struggles class, its dialectic with the development of the material productive forces, as well as the double character, broad and narrow, its manifestations. In support of his conception of culture, emphasizes how Edward Thompson conceives the relationship between base and superstructure, between social being and social consciousness and the importance attached by him to the interface between experience, hegemony and culture in the development and dynamics of social being. Also highlights the impact of their theoretical and methodological contributions to the understanding of educational objectives in urban-industrial societies and for defining the fundamentals of teaching practice today.
\end{abstract}

Keywords: Marxism; culture; education. 


\section{Trabalhonecessário}

Issn: 1808 - 799X

ano 12 , no $18-2014$

\section{Apresentação}

Apresentamos neste texto ${ }^{3}$ algumas reflexões sobre as características e fundamentos da concepção thompsiana de cultura imprescindíveis para a compreensão da relação entre história e cultura e de suas repercussões no campo educacional ${ }^{4}$. Nessa perspectiva, destacamos conceitos fundamentais para o entendimento da cultura de acordo com a tradição historicista e humanista do materialismo histórico.

\section{Características da concepção thompsiana de cultura}

Cultura, no mundo contemporâneo, vem sendo entendida de maneiras variadas. Como expressão da criatividade humana, é tida ora como erudição, ora como manifestação artística. No sentido antropológico, é concebida como um modo particular de vida, um modo específico de ser. Na perspectiva sóciohistórica, vem sendo concebida ora como um reflexo das relações materiais de exploração capitalista, ora como uma dimensão independente do ser social, dissociada das relações de exploração e de dominação.

Não existe uma tradição forte do estudo de cultura no âmbito do marxismo. Gramsci, nas primeiras décadas do século XX, na Itália, e Thompson e Williams, na segunda metade desse mesmo século, na Inglaterra, se insurgiram contra o que eles denominaram, respectivamente, de materialismo economicista,

${ }^{3}$ Este texto registra as formulações apresentadas pelas autoras na mesa-redonda "Trabalho, Educação e Experiência: a cultura como modo de vida", do seminário Trabalho, História e

Experiência de classe: Thompson 50 anos depois, na Universidade Federal Fluminense, em 23 setembro de 2013. Tais ideias são parte de um estudo sobre a concepção marxista de cultura que as autoras vêm realizando, com base nas construções teóricas de Antonio Gramsci, Edward Thompson e Raymond Williams.

${ }^{4}$ Os primeiros resultados desses estudos encontram-se registrados em dois artigos: "Materialismo histórico, cultura e educação: Gramsci, Thompson e Williams" (MARTINS e NEVES, 2013) e "Cultura, educação, dominação: Gramsci, Thompson e Williams" (MARTINS e NEVES, no prelo). 


\section{Trabalhonecessário}

Issn: 1808 - 799X

ano 12, no $18-2014$

marxismo idealista e materialismo mecânico e se somaram à tradição de crítica ativa do marxismo (MATTOS, 2012). Esta tradição ao realçar o papel da agência humana na construção do ser social acaba por contribuir decisivamente para a elaboração de uma teoria marxista de cultura que explicita como os homens, singular e coletivamente, escrevem, pela experiência vivida, a sua história.

Por se insurgirem contra o estruturalismo marxista ainda hoje predominante na esquerda ocidental, Thompson e Williams romperam com o Partido Comunista da Grã-Bretanha, contribuindo com elementos históricos e teóricos para a elaboração de outra visão do materialismo histórico, que pudesse subsidiar a construção de um socialismo designado por Thompson como socialismo humanista.

Thompson e Gramsci não sistematizaram uma teoria marxista de cultura. Ambos apresentaram contribuições decisivas para que Williams elaborasse os fundamentos teórico-metodológicos dessa teoria, por ele denominada de materialismo cultural (WILLIAMS, 1979).

Thompson considerava o conceito de cultura muito impreciso, para ele, cultura era mais uma noção geral que um conceito, pois se referia a questões muito amplas, diferentemente da conceituação, por exemplo, de classe social. Textualmente, Thompson observava que

"cultura" é um termo emaranhado, que, ao reunir tantas atividades e atributos em um só feixe, pode na verdade confundir ou ocultar distinções que precisam ser feitas. Será necessário desfazer o feixe e examinar com mais cuidado os seus componentes: ritos, modos simbólicos, os atributos culturais da hegemonia, a transmissão do costume de geração para geração e o desenvolvimento do costume sob formas historicamente específicas das relações sociais e de trabalho (THOMPSON, 1998, p. 22)

Tal entendimento da complexidade e da abrangência das manifestações culturais levou esse autor a demarcar o universo cultural para além de um sistema de atitudes, valores e significados compartilhados e também as formas simbólicas em que se acham incorporados. Ele identificou que as manifestações culturais são, antes de tudo, "uma arena de elementos conflitivos, que somente sob 


\section{Trabalhonecessário}

Issn: 1808 - 799X

ano 12, no $18-2014$

pressão imperiosa - por exemplo, o nacionalismo, a consciência de classe ou a ortodoxia religiosa predominante - assume a forma de um sistema" (THOMPSON, 1998, p. 17).

Ao realçar o caráter conflitivo das relações culturais, Thompson acena para o imbricamento entre cultura e luta de classes. De fato, essa ênfase nas contradições e lutas na análise das formações sociais contemporâneas, fez com que compreendesse que as manifestações culturais e classistas são processos histórico-sociais indissociáveis (MATTOS, 2012). Para ele,

a classe se delineia segundo o modo como os homens e mulheres vivem suas relações de produção e segundo a experiência de suas situações determinadas, no interior do "conjunto de suas relações sociais", com a cultura e as expectativas a eles transmitidas e com base no modo pelo qual se valeram dessas experiências em nível cultural (THOMPSON, 2001, p. 277, grifos do autor).

Ao conceber classe ao mesmo tempo como uma "uma formação social e cultural (...) que não pode ser definida abstrata ou isoladamente, mas apenas em termos de relação com outras classes", como necessariamente "ação e reação, mudança e conflito" através do tempo (THOMPSON, 2001, p. 169), Thompson estende a abrangência das manifestações classistas à dimensão simbólica do ser social ao mesmo tempo que acentua as dimensões política e histórica das manifestações culturais e resgata a importância do agir humano no desenvolvimento do processo histórico. Para ele,

A experiência de classe é determinada, em grande medida, pelas relações de produção em que os homens nasceram - ou entraram involuntariamente. A consciência de classe é a forma como essas experiências são tratadas em termos culturais: encarnadas em tradições, sistemas de valores, ideias e formas institucionais. Se a experiência aparece como determinada, o mesmo não ocorre com a consciência de classe (THOMPSON, 1987, p. 10).

Thompson demonstra com essa ideia que as alterações no processo histórico não se circunscrevem apenas às mudanças no desenvolvimento das forças produtivas e que os movimentos e formas de expressão populares também 


\section{Trabalhonecessário}

Issn: 1808 - 799X

ano 12, no $18-2014$

têm parte ativa neste processo. Daí decorre que, de forma não linear, as manifestações culturais traduzem tanto o estágio do desenvolvimento das forças materiais de produção da vida e das relações de produção como os níveis de correlação de forças políticas em uma determinada formação social concreta.

Com essa perspectiva teórico-metodológica, Thompson se opõe explicitamente às perspectivas de análise que consideram as práticas culturais como manifestações simbólicas, desvinculadas das relações sociais de produção e das relações de poder, ao mesmo tempo que se afasta definitivamente da tradição marxista que nega a construção histórica do ser social.

Além disso, assim como Gramsci e Williams, Thompson concebe a cultura, em sentido amplo, como modo de vida ou, mais especificamente, como modo de luta; e, em sentido estrito, como produção intelectual e artística, sentidos que se encontram na totalidade histórica. Nessa dupla perspectiva, incluem-se entre as manifestações culturais tanto as estratégias de reprodução ou transformação do ser social em seu conjunto quanto as expressões das diferentes subjetividades históricas.

\section{Fundamentos da concepção thompsiana de cultura}

As características do entendimento thompsiano de cultura, apontadas no item anterior, são consequências do modo como Thompson concebe a relação entre base e superestrutura, entre ser social e consciência social, assim como o papel da experiência e a noção de hegemonia no materialismo histórico se constituem em fundamentos para a sua concepção de cultura.

Segundo Thompson, o materialismo histórico, desde os primórdios do século XX, deveria ter se ocupado de outros aspectos que estão além da economia, como poder, ideologia, formação de consciência social, entre outros que possuem uma lógica diferente da lógica econômica, porque a análise histórica "está imersa em situações em que todos os sistemas funcionam 


\section{Trabalhonecessário}

Issn: 1808 - 799X

ano 12, no $18-2014$

conjuntamente e todos os circuitos se intercomunicam" (THOMPSON, 1981, p. 81).

É necessário considerar que o próprio Marx forneceu pistas para a compreensão da trama de relações que se estabelecem no conjunto da sociedade, mostrando que uma determinada produção e suas relações podem influenciar qualquer outra produção social e suas relações. Marx mostra ainda que a produção econômica e suas relações são simultâneas às demais produções sociais, inclusive estas podem influenciar os rumos da produção econômica e suas relações. Por isso, Thompson opta por abandonar a concepção estática da relação entre base e superestrutura, onde a base é identificada exclusivamente com o econômico e a superestrutura se constitui em seu mero reflexo. Ele considera que esta concepção conduz a um reducionismo do materialismo histórico.

Thompson, com esta perspectiva, reitera o que Marx afirma nos Grundisse:

Em todas as formas de sociedade, é uma determinada produção e suas relações que atribuem posição e influência a qualquer outra produção e suas relações. É uma iluminação geral, em que são imersas todas as cores e que modifica suas tonalidades particulares. É um éter especial a definir a gravidade específica de tudo o que dele se destaca (MARX, apud THOMPSON, 2001, p. 254, grifo nosso).

Thompson não duvida da importância da produção econômica para compreender as relações sociais capitalistas. O que ele questiona é a possibilidade de analisar e descrever um modo de produção em termos econômicos, sem considerar as normas, os ritos, as ideias e os valores que compõem uma cultura, porque estes aspectos são fundamentais para a compreensão das relações sociais.

Por isso, ele destaca que existe uma interação recíproca entre base e superestrutura. Num determinado contexto histórico e social, as determinações materiais estão articuladas aos elementos subjetivos. As mudanças nas relações produtivas repercutem nas ideias e valores humanos, por isso são efetivadas na 


\section{Trabalhonecessário}

Issn: 1808 - 799X

ano 12, no $18-2014$

vida social e cultural. Assim, não há "uma prioridade heurística das necessidades e comportamentos econômicos diante das normas e sistemas de valores" (THOMPSON, 2001, p. 252-253).

Thompson demonstra que as relações sociais que compõem uma sociedade têm várias nuances e representam a articulação entre o subjetivo e o objetivo. Há uma dialética da dinâmica social que não pode ser compreendida a partir de uma metáfora, como a concepção de base e superestrutura que exclui os atributos humanos (THOMPSON, 2001), porque se assim o fizer ter-se-á uma imagem distorcida da realidade social. Lembra que a dialética da dinâmica social expressa lutas e conflitos entre as diferentes classes sociais, por isso é necessário considerar as ações humanas para compreender o nexo relacional entre o econômico e o não econômico, ou seja, entre os fenômenos sociais e culturais e as relações de produção, caso se queira resgatar a dialeticidade de uma determinada sociedade.

Ao trazer as ações humanas como elemento fundamental na construção do materialismo histórico, Thompson enriquece o entendimento da relação entre ser social e consciência social. Nesse sentido, ele destaca que o ser humano real, com suas ações, relações e contradições, é o objeto de estudo central da teoria marxista. Analisa como homens e mulheres experimentam, em diferentes períodos históricos, situações e relações produtivas determinadas, fruto de necessidades, interesses e antagonismos. Estas experiências estão presentes em sua consciência e sua cultura e os fazem agir numa situação determinada (THOMPSON, 1981).

Ele mostra também que pensar e ser são atividades inerentes aos seres humanos, seres que simultaneamente pensam, sentem e agem. Há um diálogo constante entre consciência e ser, este atua na formação da consciência e aquela também interfere no ser. Por isso afirma que existe "uma organização cognitiva da vida correspondente ao modo de produção e às formações de classe historicamente transcorridas" (THOMPSON, 2001, p. 260). 


\section{Trabalhonecessário}

Issn: 1808 - 799X

ano 12, no $18-2014$

Thompson destaca também como é importante entender a complexidade da relação entre pensar e ser na história porque "há um sem-número de contextos e situações em que os homens e mulheres, ao se confrontar com as necessidades de sua existência, formulam seus próprios valores e criam sua cultura própria, intrínsecos ao seu modo de vida" (THOMPSON, 2001, p. 261).

Em síntese, essas reflexões de Thompson mostram que dois diálogos são fundamentais para o conhecimento histórico de uma sociedade: o diálogo entre o ser social e a consciência social, que dá origem à experiência, e entre "a organização teórica (em toda a sua complexidade) da evidência, (...) e o caráter determinado de seu objeto" (THOMPSON, 1981, p. 42).

É necessário destacar que ocorrem mudanças no ser social que dão origem à experiência modificada; e essa experiência é determinante, no sentido de que exerce pressões sobre a consciência social existente, propõe novas questões e proporciona grande parte do material sobre o qual se desenvolvem os exercícios intelectuais mais elaborados.

Thompson considera a experiência uma categoria fundamental para compreender a relação entre ser social e consciência social. Ele mostra como a experiência exerce pressão na formação da consciência social. Pois

a experiência é um termo médio necessário entre o ser social e a consciência social: é a experiência (muitas vezes a experiência de classe) que dá cor à cultura, aos valores e ao pensamento: é por meio da experiência que o modo de produção exerce uma pressão determinante sobre outras atividades: e é pela prática que a produção é mantida (THOMPSON, 1981, p. 112).

Tanto homens quanto mulheres vivem situações e relações produtivas determinadas, fruto de necessidades, interesses e antagonismos, e estas experiências estão presentes em sua consciência e sua cultura do modo mais complexo possível e os fazem agir numa situação determinada (THOMPSON, 1981). 


\section{Trabalhonecessário}

Issn: 1808 - 799X

ano 12, no $18-2014$

A categoria experiência é importante e indispensável, pois expressa uma resposta mental e emocional de um indivíduo ou de um grupo social a acontecimentos inter-relacionados ou a repetições do mesmo tipo de acontecimento. Mas deve-se frisar que a experiência é válida e efetiva, mas dentro de determinados limites, porque ela "surge espontaneamente no ser social, mas não surge sem pensamento" (THOMPSON, 1981, p. 16). Os homens têm a capacidade de refletir sobre a sua experiência. Assim há uma possibilidade constante de mudança nas experiências vividas pelos homens, ou seja, essa experiência modificada exerce pressão sobre a consciência social, ou seja, o ser social determina a consciência social, "à medida que a experiência se impõe ao pensamento e o pressiona" (THOMPSON, 1981, p. 34).

Segundo Thompson, a transformação histórica acontece pelo fato de as alterações nas relações produtivas serem vividas na vida social e cultural, de repercutirem nas ideias e valores humanos e de serem questionadas nas ações, escolhas e crenças humanas. Existe uma indissociabilidade entre cultura e experiência, mesmo porque os valores e ideias são aprendidos na experiência vivida e estão sujeitos à determinação do que é vivido, mas Thompson alerta que os homens têm a capacidade de pensar e discutir sobre os valores aprendidos, assim como têm a capacidade de fazer escolhas, por isso as "pessoas são tão determinadas (e não mais) em seus valores quanto o são em suas ideias e ações, são tão "sujeitos" (e não mais) de sua própria consciência afetiva e moral quanto de sua história geral. Conflitos de valor, e escolhas de valor, ocorrem sempre" (THOMPSON, 1981, p. 194).

Thompson destaca ainda que as pessoas vivem suas experiências como sentimentos e lidam com esses sentimentos na cultura, como normas, obrigações familiares e de parentesco, e reciprocidades, como valores ou (através de formas elaboradas) na arte ou nas convicções religiosas (THOMPSON, 1981).

A formação da consciência social está imersa em tensões e embates, há uma relação constante entre ser social e consciência social nos diferentes tempos 


\section{Trabalhonecessário}

Issn: 1808 - 799X

ano 12, no $18-2014$

históricos, ou seja, a consciência social apresenta, muitas vezes, ambiguidades, porque ela se constrói a partir das experiências vividas nas relações sociais. É preciso destacar que a consciência de classe se forma em tempos e lugares diferentes e nem sempre da mesma forma (THOMPSON, 1987).

Assim, a experiência é fundamental para a compreensão da formação da consciência no interior das relações sociais, pois ela funciona como um elemento de junção entre cultura e não-cultura, entre experiência vivida e experiência percebida (MATTOS, 2012).

A categoria experiência confere dinamicidade à realidade social e faz perceber a atuação da agência humana no processo histórico. Para Thompson, a lógica de um processo "só pode ser revelada na observação do processo no tempo, como também cada momento, cada "agora" ("conjuntura") não deveria ser considerado como um momento congelado da interseção de determinações múltiplas subordinadas e dominantes ("sobredeterminações"), mas como um momento do vir-a-ser, de possibilidades alternativas, de forças ascendentes e descendentes, de oposições e exercícios opostos (classes) de sinais bilíngues" (THOMPSON, 1981, p. 117).

A preocupação de Thompson era apresentar a relação complexa entre a determinação das relações sociais e a dimensão cultural da consciência de classe, pois os homens devem ser vistos como sujeitos de sua própria história, e para realizar a mediação entre a determinação das relações de produção e a consciência de classe, ele elegeu a experiência.

Ao fornecer dinamicidade e dialeticidade à relação entre ser social e consciência social, a experiência conduz o processo de hegemonia e as formas de dominação e controle da classe dominante e o seu embate com a classe dominada. Pois, raramente, uma classe dominante exerce sem mediações a sua dominação. A noção de hegemonia se constitui, portanto, em fundamento privilegiado na construção de uma teoria relacional de classe e, concomitantemente, de uma teoria marxista de cultura. 


\section{Trabalhonecessário}

Issn: 1808 - 799X

ano 12, no $18-2014$

Thompson e Williams buscaram nas reflexões gramscianas sobre as formas de dominação política nas sociedades capitalistas os suportes teóricometodológicos para o desenvolvimento de suas ideias sobre a relação entre cultura e hegemonia. Tais reflexões fizeram com que Thompson pudesse constatar que "o poder de classe poderia agora ser visto não mais como uma mera ditadura mal disfarçada, mas em formas muito mais sutis, penetrantes e, consequentemente, compulsivas" (THOMPSON, 2001, p. 148).

Para ele, a hegemonia perpassa os processos históricos gerais, abrangendo os aspectos materiais e simbólicos da luta de classes. Nesse sentido, ela é política e é também cultural. Ao utilizar a noção de hegemonia como categoria de análise para a compreensão das relações sociais inglesas do século XVIII, mais especificamente, para o entendimento do processo de formação da classe operária inglesa, Thompson reforça o duplo caráter coercitivo e consensual inerente às relações de poder no capitalismo, desde os primórdios da industrialização, desfazendo uma falsa impressão de que as formas hegemônicas de dominação cultural e política são manifestações específicas das relações de poder do capitalismo em sua fase monopolista. $\mathrm{O}$ autor afirma textualmente que só "muito raramente - e, neste caso, apenas por pouco tempo - uma classe dominante exerce, sem mediações, sua autoridade por meio da força militar e economicamente direta" (THOMPSON, 2001, p. 239).

Thompson rejeita ainda a visão de alguns estruturalistas e marxistas de que a hegemonia impõe uma dominação abrangente dos governados, ou de todos aqueles que não são intelectuais. Para ele, as experiências de dominação são revogáveis. Os subordinados são capazes de corrigir as categorias de subordinação implantadas em seus corações e mentes desde o nascimento, por meio de um processo abrangente de formação voltado para a construção de uma contra-hegemonia cultural e política em aparelhos privados de hegemonia.

Ele observa também que os aparelhos privados de hegemonia cultural, como Igreja, escola e mídia, agem no domínio do doméstico, enquanto os 


\section{Trabalhonecessário}

Issn: 1808 - 799X

ano 12, no $18-2014$

aparelhos de hegemonia política atuam no domínio do público. Ressaltou ainda que esses aparelhos privados de hegemonia cultural atuam, muitas vezes, no sentido de dificultar o acesso ao domínio público, ou seja, no sentido de inviabilizar que a contra-hegemonia venha a se tornar uma possibilidade histórica (THOMPSON, 2001).

No entanto, adverte que limitar a contra-hegemonia ao domínio do político é estar fadado ao fracasso, já que aspectos subjetivos da nova sociabilidade histórica assumem papel decisivo na construção de um novo projeto de sociedade e de sociabilidade. Dessa forma, para Thompson, o singular e o coletivo, o doméstico e o público se imbricam em um projeto de formação humana e de transformação societal.

\section{Repercussões na educação}

As contribuições teórico-metodológicas de Thompson quanto à natureza das manifestações culturais nas sociedades contemporâneas oferecem pistas seguras para a compreensão das propostas educacionais nas sociedades urbanoindustriais e dos fundamentos da prática pedagógica na atualidade.

Por ser uma expressão específica das práticas culturais, a educação engloba necessariamente aspectos objetivos e subjetivos da formação humana, constituindo-se, simultaneamente, em prática simbólica e força produtiva. Nessa dupla e indissociável perspectiva, desempenha papel estratégico na conformação dos padrões da sociabilidade dominante e na reprodução ampliada da riqueza nas sociedades urbano-industriais contemporâneas.

Se existe uma interseção entre cultura e luta de classes, existe também uma imbricação entre educação e classe social. Tanto em sentido amplo, como educação política, quanto em sentido estrito, como educação escolar, a questão educacional está imersa nos embates das relações sociais capitalistas e é um instrumento poderoso de obtenção do consenso das classes exploradas para o 


\section{Trabalhonecessário}

Issn: 1808 - 799X

ano 12, no $18-2014$

projeto político das classes hegemônicas no mundo contemporâneo. Entretanto, dependendo do nível de organização das classes subalternas e das experiências vividas de construção de novas relações sociais, a educação pode ter um papel privilegiado na construção de um projeto de transformação do ser social.

Com base nesse entendimento sobre as possibilidades históricas da educação, Thompson empreendeu críticas ao projeto educacional desenvolvido na Inglaterra de meados do século XX. Fez o mesmo com a postura políticopedagógica dos educadores, especialmente porque não consideravam o papel importante da experiência dos seus alunos no processo ensino-aprendizagem, o que provocava uma dicotomia entre cultura letrada e experiência no processo educacional das classes trabalhadoras, reforçando o projeto burguês de conservação das relações sociais.

Thompson (2002) enfatiza ainda a dialética entre educação e experiência. Para ele, nenhum educando pode ser visto como um recipiente passivo. Com base em sua prática educativa, como educador de adultos, ele percebeu que a experiência era importante porque pode modificar

às vezes de maneira sutil e às vezes mais radicalmente, todo o processo educacional; influencia os métodos de ensino, a seleção e o aperfeiçoamento dos mestres e o currículo, podendo até mesmo revelar pontos fracos ou omissões nas disciplinas acadêmicas tradicionais e levar à elaboração de novas áreas de estudo (THOMPSON, 2002, p. 13).

Essas reflexões sobre a prática pedagógica se incluem entre as estratégias políticas para a construção de um socialismo humanista, uma vez que uma formação humana emancipadora "se faz" na interseção entre história, trabalho, política e cultura.

Tais reflexões educacionais de Thompson se constituem também em poderoso instrumento de análise dos desdobramentos educacionais ocasionados pelas mudanças na base técnica e nas superestruturas das formações sociais contemporâneas, provocadas principalmente pelo espraiamento acelerado das 


\section{Trabalhonecessário}

Issn: $1808-799 X$

ano 12, no $18-2014$

tecnologias de informação e de comunicação do âmbito da produção material para o conjunto das relações sociais; pela mundialização da produção material e simbólica da vida; e pela mercantilização também acelerada dos bens simbólicos que requerem da formação humana novas determinações técnicas e éticopolíticas. 


\section{Trabalhonecessário}

Issn: 1808 - 799X

ano 12, no $18-2014$

\section{Referências:}

MARTINS, Angela Maria Souza; NEVES, Lúcia Maria Wanderley. Materialismo histórico, cultura e educação: Gramsci, Thompson e Williams. Revista HISTEDBR (on-line), v. 13, n. 51, junho 2013.

. Cultura, educação, dominação: Gramsci, Thompson e Williams. No prelo. MATTOS, Marcelo Badaró. E. P. Thompson e a tradição de crítica ativa do materialismo histórico. Rio de Janeiro: Editora UFRJ, 2012.

THOMPSON, E. P. A Miséria da Teoria ou um planetário de erros: uma crítica ao pensamento de Althusser. Rio de Janeiro: Zahar, 1981.

. A formação da classe operária. v. 1. Rio de Janeiro: Paz e Terra, 1987.

. Costumes em comum. São Paulo: Companhia das Letras, 1998.

. As peculiaridades dos ingleses e outros artigos. Campinas: Editora da Unicamp, 2001.

. Os românticos. Rio de Janeiro: Civilização Brasileira, 2002.

WILLIAMS, Raymond. Marxismo e literatura. Rio de Janeiro: Zahar, 1979.

Recebido em maio de 2014

Aprovado em junho de 2014 